\title{
Javanese Personal Cars Consumer Behaviour (This article is developed from a part of doctorate thesis of the author)
}

\section{Rini Astuti}

Department of Management, Faculty of Economics and Business, Universitas Gajayana, Malang, Jawa Timur, Indonesia

\section{Abstract}

Culture is one of the key factors that directs or even determines consumer behaviour. Behaviour is related to various things, including behaviour towards consumer goods, such as cars. Therefore, in the field of economics, especially management, there is a discipline that specifically studies consumer behaviour. This study aims to reveal the behaviour of Javanese consumers towards passenger cars. This research was conducted in Malang City, utilizing a qualitative research design and analyzed using Peircean semiotics. The result shows that how men and women interpret their personal cars are generally similar, with slight differences.

Corresponding Author:

Rini Astuti

riniastuti@unigamalang.ac.id

Published: 29 July 2020

Publishing services provided by

Knowledge E

(c) Rini Astuti. This article is

distributed under the terms of

the Creative Commons

Attribution License, which

permits unrestricted use and redistribution provided that the original author and source are credited.

Selection and Peer-review under the responsibility of the WCGS Conference Committee.

\section{G OPEN ACCESS}

Keywords: personal car, Javanese, Peircean semiotics, gender

\section{Introduction}

A car is a symbol for their owner. People buying or owning a car must have personal reasons. For example, someone may have a car, but does not actually need it as a means of transportation. The car is only used in certain times. This means that car owners do not consider the element of efficiency in the ownership of a product. The benefits of ownership here are not based on the consideration of efficiency from its primary function.

In Javanese society, a Javanese man is considered to have a perfect or complete life if he has a turangga (horse), in addition to, for example, having a woman and power. Cars, for Javanese, are included in turangga. If in the past horse was used as a vehicle or mean of transportation, today, in its development, a car is one of the means of transportation. This is why cars are included in turangga.

The important thing to note is that everyone who has a mean of transportation, especially a car, tends to have different reasons, even though the vehicles are of the same brand and type. In other words, the owners interpret their car differently. In a study 
conducted by Amirat [1], the reasons why people own a car were listed. Some of the reasons are, for example, because of inheritance or unforgettable events. This shows that the price, features, and especially advertising influence, do not the main reason to have a car.

In this study, the interpretation is extracted from the symbol owned by someone, which in this case is the personal car in ownership. Meanwhile, in relation to culture, it can be said that the culture of a region greatly influences the behaviour of its people. A marketer must know about the information regarding the culture of their marketing area if they want their products to sell in the market. However, only knowing about the culture is not enough. Cultural interpretation needs to be studied in order to better understand the culture so that there are no mistakes in marketing decision making. Applying this to the biggest tribe in Indonesia, the Javanese, is not easy. This tribe has a different ethics from the Western: they are not always open, symbolic, and they face their problems with a smile.

In relation to the patriarchal culture that exists in Javanese society, there has been a slight shift even though it still applies in principle. This is caused by the increasing number of women who are able to get (higher) education. A high level of education gives women the opportunity to work outside their house. As a result, they are able to earn their own income. This allows them to purchase a car with their own money simply by telling their husband about it. Such circumstance is certainly interesting to be explored.

Meanwhile, Suryadi [11] said that, in the past, Javanese society measured the success of a Javanese man in having a perfect/complete life based on his ownership of five things, namely: wisma (house), turangga (horse), curiga (weapon), kukila (birds), and garwa (wive). Should all five are owned by a Javanese man, he can then be said to be a $100 \%$ Javanese knight or considered as a symbol of virility.

The Javanese are known for their patriarchal culture. In societies that embrace such culture, gender relations have restrictions, which makes the position and role of men more dominant than women. Following this reality, many people consider that men have special position and are seen as the head of the household.

Recently, there has been a shift of position and gender relations in Javanese society. The advance of education, modernization, women emancipation, and the influx of Western cultural influences have shifted the pattern of gender relations which generally causes cultural values to change from what they previously were. This certainly can affect the lives of Javanese people. 
The fact that there are changes in terms of gender relations is undeniable. However, despite the changes, Javanese values and concepts of women still live in the minds of many Javanese in urban and rural areas. In daily life, whether we realize or not, women still do what the women of previous generation used to do, despite the shifts and adjustments. This concept can support, or otherwise become an obstacle in the efforts to improve the position and role of Javanese women. How the changes affect personal car ownership are interesting to analyze.

Nowadays, car is no longer solely a mean of transportation. Car has become a lifestyle and a measure of social status because to own a car in general is not easy. The better the car or the more number of cars owned, the higher the economic status of the owner because they reflect their owner's wealth. In addition to that, there are also other benefits of having a car in social terms and happiness, and it increases the prestige of its owner.

A product can be used to reflect the owner's identity and can be used to achieve what people expect them to be. So, the product that someone buys is nothing but to encourage the owner's self-concept as it contains symbolic value.

A product is seen by consumers as a symbol because of its ability to communicate the consumers to others. There are three characteristics of communicative products. First, the product is visible. It's important that it is visible to others during their purchase, consumption and disposition. Second, the product has variability. That is, what some consumers can afford to buy, other people might not. Third, the product symbolically has a personality. Personal symbol refers to how far a product can represent the stereotype image of its owner in average.

So, the important thing is in one's relationship with material world. Materialism refers to how a consumer pays attention to worldly possession which is important as their identity and for their life. Great material ownership is the centre of people's lives and the greatest source of satisfaction and dissatisfaction. What people have is a part of themselves or it can be said that a person is whole with all they have. One kind of ownership that can help in the formation of personal feelings is ownership of objects. It is important to have a house, car (for men), and favourite clothes (for women). Only from the car they drive and the clothes they wear, it can be seen what kind and who the person is [10]. In short, this study aims to uncover the behaviour of Javanese consumers towards their personal cars. In this way, we can understand and recognise their different attitudes toward their personal cars. 


\section{Methods}

\subsection{Research Locations, Data, and Informants}

The research location is Malang City. The data of this study were obtained by utilizing information from and observations on subjects with Javanese ethnicity. The data collection technique used in this research is snowball technique [7]. Informants were selected on a rolling basis until they indicate the level of information saturation. This research was conducted by interviewing and observing 23 Javanese men and 14 Javanese women. The amount is based on information obtained which has reached high enough similarities so that it is assessed to have reached the saturation point. In accordance to the location of the study, the informants were limited to those who live in Malang city. They were chosen based on the criteria of being a Javanese descendant, at least from one of their parents, and the second generation who own a personal car. What is meant by owning a personal car is to have control over the car as their own personal right. Based on these criteria, age, education, employment, and income are not restricted.

\subsection{Data Validity}

To avoid researcher mistakes in qualitative research and to obtain accurate information so that its validity can be relied upon, triangulation is applied. Another term for triangulation is the confirmation of information, both with the informant - as presented in the second interview stage and onwards - as well as the theory that is used as a conceptual basis. Relevant experts can also be involved in triangulation. This is to avoid mistakes due to the subjectivity of researchers. The purpose of triangulation is to earn the honesty of the informants, the accuracy of information understanding, and the validity of the interpretation based on the analysis. In addition to that, comparison and checking of the degree of trustworthiness and reliability of information between observational data and interview results are also carried out [3]. The triangulation can also be done by discussing information obtained by researchers with experts. The expert chosen must naturally be related to the information in question. With the implementation of these techniques, the validity of information can be guaranteed [8].

In this study, two types of triangulation were carried out. First, the triangulation of information is carried out in the form of confirmation with the informant. If the answer seems to be consistent then the data confirmation is stopped. However, if the consistency hasn't been achieved, then it will have to be confirmed again. For each informant, how many times the confirmation is done is not the same as it all depends 
on their answer and subjectivity of the researcher. Second, the triangulation of experts was carried out by meeting two experts, in the field of semiotics and Javanese culture. This step is taken to discuss the validity of the analysis in the form of interpretation of information and its suitability with the concept or theory used.

The next step is matching data from the informant's interview results. If any are found to be incompatible, the data and analysis that have been carried out will be examined again until the reasons for discrepancies and solutions are found. This is also done by triangulation of theories, namely theories of consumer behaviour or theories of Javanese culture.

\subsection{Data analysis}

Data analysis in this study uses Peircean semiotics model. Peircean semiotics model is presented in a triangle of interpretation (Triangle), which, according to Christomy [2], consists of representament (something that can be captured by senses, appearance/forms of personal cars), objects (concepts related to the existence of personal cars), and interpretant (interpretation according to the user). Because the user of the symbol is the determinant that indicates their behaviour, Peircean semiotics is called pragmatic semiotics.

Based on this concept, the steps of data analysis are as follows.

1. Representament in the form of personal car products, which are captured by the subject (owner) as the object of a tool that can be used to support their mobility from place to place. Although, there are some differences in the behaviour of car owners between one and another as a result of his interpretation, interpretant [6].

2. This interpretation is then manifested in the final act of having a personal car. Once owned, the next action is to use and care for the personal car to meet its needs. In other words, the series of actions of the owner shows the treatment of the ownership of the personal car and is an interpretation expression of the personal car they own. From where the person saw/got a glimpse of a personal car to the point when he can own it also varies, for example from inheritance, neighbours' cars, car showrooms, etc.

3. The act of owning and treating a personal car is analyzed using the Peircean semiotics model because this it sees or has the notion that something is considered a symbol if the symbol itself is responded to by the subject (person), so that he or she performs an action related to the symbol in question (response or consumer 
behaviour towards the personal car/product). In Peircean semiotics there are icons, indexes, and symbols [12].

4. All three (icons, indexes and symbols) are used to see the sign in relation to the ownership of a personal car. Then it was interpreted further with theories of Javanese culture (turangga) interpretation.

5. From the interpretation, a description of the meaning of a personal car is obtained [5]. As stated in the preposition, the meaning of the car can vary.

6. No matter how diverse the interpretations of personal cars are for their Javanese owners, there must be some similarities between them. These similarities are the common thread that binds various interpretations so that it can be concluded.

\section{Result and Discussion}

\subsection{Views on Cars (Turangga) Based on Gender}

Man was created by God, male and female, biologically different. Each sex has different physical characteristics and strengths. In their gender roles, people are familiar with the terms masculine and feminine. Masculine is for men, while feminine is for women.

In general, men want personal cars that look gallant, macho, stocky, fierce, and the like, while women want cars that are elegant, beautiful, mriyayèni, and so on. However, in reality there are some female informants who like a masculine personal car, whereas men want a feminine car. In Jung's research, adapted by Handayani \& Novianto [4], it was found that there are no real psychological differences between men and women. The differences only arise due to the influence of culture and community beliefs. Furthermore, Jung believes that both men and women actually have some elements of their opposite sex. Women have masculine aspects in themselves and men have feminine aspects in themselves. This supports the finding of women wanting a masculine car, while men want a feminine car. For more details, the following section is a description related to the problem.

\subsection{Women's Views of Cars}

Informant SM repeatedly said that a personal car should be manly, but beautiful. When asked the reason why women would choose manly cars, she replied, "... to be different from others, I'm not a mainstream person." According to this informant, the colour of a 
manly car is black or it can also be an unusual colour, yellow for example, is very cool. The car that according to the informant can fulfil her wish or her dream car is a Jeep Wrangler.

A similar opinion was expressed by informant $\mathrm{MH}$, who is tall, big, and likes to wear trousers rather than skirt. Recent development and feminism have made Javanese women's insights on womanhood (femininity) change. This change apparently also affects the selection of the type of car, including informant $\mathrm{MH}$ who chose the Escudo. When asked why she chose Escudo, she answered that:

Escudo is a manly car. I like Escudo, because it is gedhé (big) fits my posture.

Even so, she also admitted that wong wédok Jawa iku kuduné lembut (Javanese women are supposed to be gentle.), manly is not woman's posture but man's. Regarding the colour of the car, MH likes them white because it is beautiful but manly. Although she likes a manly car, MH still applies a beautiful element that is characteristic of a woman.

Her statement is in line with the opinion of informant MA, who owns a Jeep Katana. The reason MA uses the vehicle, just like SM, she also wants to be different. This car can fulfil the wishes of the informant to look cool, happy, and dashing. She mentioned that her husband said, "... you drive like a cow boy, a jeep is more suitable for you." Although she likes jeep, it's not because of their large size. Her reason was because a Katana is cèkli, small and agile. To strengthen the appearance of the car, the wheels are replaced with larger ones so it is not hard (comfort considerations). As a result, the shape of the car- a Jeep, $4 \times 4$, with large wheels- became rough-looking. Thus, their car appears to be a symbol of gallantry.

Similar to the three previous informants, FP has two jeeps. The informant who wanted to be a brave, tough, and strong woman in her youth realized her desire by type of vehicle she has, namely the jeep. This mother of two children stated that "... my cars are like my feet, so they must be healthy," which makes maintenance being prioritized. Since she feels comfortable with jeep, she still chooses this type until now. It was further said that "... current jeeps aren't like how they were in the past, they are now more comfortable." Women like jeeps, because they are manly but beautiful. They are considered to have the element of beauty. They're also for all terrain. Thus, the conclusion is to the symbol meaning. 


\subsection{Men's Views of Cars}

Sedans are often advertised by beautiful and delicate women so they seem feminine. However, there are men who like this type of car. When asked for the reason it turned out it wasn't because of their femininity but because the sedans also give an elegant impression. Meanwhile, informant WM stated that many officials use sedans as official cars which make it seem to be authoritative.

Informant KPS chose a sedan as his first car. When he got another car to replace it, he did not choose another sedan, not because he no longer liked them, but rather the practical reasons for its use so he chose a city car, which still has a resemblance to the sedan. Even though he admitted that it's more feminine, the informant still likes it because it's small, which makes it agile and ènthèng (light); its small body is suitable for use on increasingly crowded streets. As he said: "I like the shape, which is actually feminine." The small car also fits in the garage of his house. When he first bought a car he wanted a sedan. Informant felt that it's more appropriate to use in commuting to campus (as a lecturer) as a civil servant. He stated that going to campus by sedan is cooler than panther. When asked more about his dream car, the answer was:

I like Jeep Robicon, because it looks handsome, manly, and I like its shape the most. I like it because it's strong, tough, and has big cc.

Informant SM likes sedans because of his family habits from when he was young (a child), as he said:

... accustomed to it since at home, since I was in the secondary school, high school they were all sedans, even now, at home (my parents) mostly use sedans.

This informant had tried the Diesel Kijang, thinking he might like it. It turned out that the informant's wife said that "... why is the sound like this, unlike sedan." In the end it was sold and he went back to buying sedan. When asked about his dream car, the informant's answer was "... sedan, black or white." Thus, cars have symbolic meanings, because they symbolize valour, gallantry, and beauty. Informants who chose sedan didn't choose because of its femininity, but elegance. So it's back to the symbolic interpretation. 


\subsection{Cars By Peircean Semiotic Category}

Peirce developed pragmatic philosophy through semiotic studies. Peirce's opinion states that the science of symbol is formed by three parties, namely representament, objects, and interpretants. Semiotic function is to explore interpretation. The advantage is that the explored interpretation is broad, depending on the extent of people's arguments. With that perspective a car's interpretation for its owner varies greatly and the following description presents this.

\subsubsection{Car Shows Status (Prestige)}

There was an interesting statement regarding a car our informant has. Informant $\mathrm{MH}$, for example, indirectly stated that there is a sense of satisfaction from driving a car compared to motorcycle. That is a form of prestige. This informant claimed that it feels different going to an official event by motorcycle compared to car. What's more, from his experience at his previous workplace, the entrance for the motorcycle rider is at the back, in contrast to the cars', which is in front of the building. "I feel that it is more prestigious to be there" he argued,

... there are certain moments that appreciation is important, but not always, when I want to earn more respect, I use a car.

Meanwhile, informant AS stated that:

... a car reflects our status, because I am more focused on my work. Being a seller of services, and having companies as most of my customers, when we visit them we really have to bring a good car because it turns out there is a strong correlation between the car we use and the results of the negotiations. My job demands me to look different when I meet with clients, so I have to use a good car. Bringing a good car makes them trust and respect me more.

AS further said that among Javanese people, especially in rural areas, owning a car is a proof of their success, he said that:

Someone said that, [if] they don't have a car, they won't go home. As a symbol of worldly success, it is important to go home by car for Lebaran.

Responding to such opinion US said:

For me it doesn't matter, even if my friends go by cars, going by motorcycle is not a problem to me. 
When further asked about other issues related to certain events, for example, attending a wedding invitation or reunion, he replied, "I think it is necessary to adjust, too, accompanying the bride and the groom is also the same."

Despite disagreeing to the opinion, he, in fact, owns cars himself. This is a fact that must be addressed critically. Should he not have a car at all, would he also be able to go home for Lebaran with the same feeling? The answer is obviously no. Thus, owning a car still adds value to one's social status.

However, this also does not mean that his car is used as the only measure of worldly success to him, because there are still other things that are also considered, following his statement when asked about the measurement of one's success according to Javanese culture. He mentioned some shifts in his answer to this question,

... the Javanese used to measure the success of their lives, five philosophies (curiga, wisma, turangga, garwa, and kukila), but now it has shifted to the achievement of higher education, degrees, being a professor, and others. Even though these people do not have a car, Javanese will still think 'Wow, how successful they are:

Both informants, at certain times prioritize prestige, as informant $\mathrm{MH}$ mentioned (feeling satisfied driving a car rather than motorcycle, and more respected. This is indicated by the separate entrances for the vehicles). Informant AS (getting what he wants when meeting with a client, because a good car convince the client to trust him, so important deals related to his work are carried out). The opinions of these two informants in interpreting their personal car prioritize material elements, because to get/buy a good car or a specific car would require more money than buying a motorcycle. Following Peircean semiotics, this case falls into the index category. The index here means cause and effect, expensive cars can only be owned by rich people, to earn more trust from their clients. The appearance of the informant both from the clothes worn and the car they drive can convince the client or others trust or respect him.

There is one Javanese proverb saying ajine diri saka lathi, ajining raga saka busana. This proverb contains two parts. According to first part of proverb, ajine diri saka lathi, respect to other people should be based on how they act i.e. how they talk, the way they talk, their body language. The deeper meaning of how they act is that an act itself is something related to non-physical things. The second part, ajining raga saka busana, mentions that people judge other people with how they dress, which itself shows something related to physical things. These physical things usually come with 
monetary value as part of its attribute. The more valuable the physical things in question, the higher its monetary value are. Person who shows this physical thing, e.g. car, as part of their identity also showing it as part of their status symbol. The more luxurious their car the more respect they gains in society. In relevant to this theory, AS do not share the same perspective. The actual reason he buy his car is because of his occupation, mainly to place himself in the same level as his clients. In his daily life however, AS do not usually take appearance in top priority. He says:

... motorcycle is preferable to me because it is more practical, more efficient and commutes faster rather than car when I need to attend formal events like wedding

An exception can be made if there are special events

... as a professor, sedan is more suitable to be used as a transportation method to campus

Just like previous interviewee, $\mathrm{HY}$ also gives opinion that his current car (Kijang, Terano, Yaris) suits him well. Another interviewee, $\mathrm{AH}$, also shares the same opinion, mentioning that his Innova is enough for him. The word enough for him have relationship with how he views his car as a form of gratitude to God. According to him, when someone has enough money, they should also upgrade their appearance and general taste. At some level, they should dress more stylishly, using more gears that shows a refined preference and drive high quality cars. He says "gengsi itu perlu, tetapi sedikit saja" which roughly translates to "show off is necessary, for just a little bit."

IS and Mg also shows similar view. IS says:

... having ownership of a car, one of the reason is to stay relevant to their peers. When you are not doing that I feel it is kind of inappropriate. You have respectable job, your rank are high. Owning small car or even don't have any sounds sad and could be detrimental to your reputation.

Mg voices her opinion about making impression:

I agree that making impression is necessary because it is one of the things that other people use to judge in a quick manner. More of importance when you attend meeting with your client or going to discuss business with other important pers. 


\subsubsection{Colour of Cars Are Related to Your Preference}

As one of primary trait of a car, colour is something that people will discuss. It is irresistible not talking about colour when someone wanted to purchase a car. This element is also one of key points when conducting an interview. Sometimes there are relationship between colour of a car and its psychological impact to other people which the interviewee wanted to show.

According to the data, male interviewee sees the colour black as a symbol of wealth, intimidation, elegance, immortal, reputable, elegant, and also scary. If we analyze based on psychology of colour, black gives feeling of gloomy, dark, scary, mysterious, independent, tranquil, and also elegant. We can see that there are two similar traits, scary and elegant.

From observation it also shows that black colour also used in high-ranking people e.g. officials, prime minister, and president. Even Queen of England uses black-coloured car. Limousine, a very expensive car, also mostly coloured black, as do government officer's car. Black colour also used in various car that promotes 'sporty' and also jeep as it boosts its degree of scariness.

Black as a base colour will look tacky and can be very contrasting. Interviewee who think this way said that cars that are black will be more visible in contrast if combined with accessories. For example, $\mathrm{AH}$ thinks that by giving the door handle accessories it will look very elegant. Other interviewee, Sp, who follows car news as a hobby said that making black colour looks shiny is easier than other colours. If you want to treat a black car, the results of the treatment can be more visible. Although black car is more difficult to maintain because it easily looks dirty, black enthusiasts are numerous, both in lower and upper classes. There was also an interviewee who said that the black makes it not easily boring (EB).

Other preferences certainly exist. The following interviewee, for example, considers that yellow colour is masculine. When reflected from the psychology of colour, yellow gives the impression of excitement, bright, bright, shining, and firmness. It was these impressions that directed KL's opinion that he interpreted the yellow colour to be masculine. When the colour is painted to his jeep and its wheel are made bigger, the impression of masculine becomes stronger. Apparently, the yellow colour turned out to be the colour of the first car he had, so the yellow colour was also a memorable for him.

Another interviewee points out that the colour of silver gives cold impression compared to white colour. White is brighter than silver and will feel more so if it accumulates 
dust. White car still feels cold when compared with black. Black cars can become hot quickly because black colour absorbs the sun's heat. Using air conditioner is enough for a solution. Silver and white do not absorb heat. In terms of colour psychology, silver colour creates the impression of glamour and expensive, because it has relationship with silver as a material.

Regarding white, KPS interpreted this colour as bright, pleasing to the eye, and comfortable to look at. White gives an impression of purity and clean which gives the impression of freedom and openness. One interviewee, Sp, said that previously, white colour was not seen as attractive. Only recently that white colour feels like trending. White colour can also gives impression of healthy because white usually are clean.

There is an interviewee who likes red, either blood-like red or brighter red (Mr). Red is a symbol of courage and pride, according to him. Meanwhile, when viewed from a psychological perception, red gives the impression of warmth, happiness, courage, enthusiasm, strength, excitement, dynamism, communicative, joy, energy, action, and warning signs. In addition, bright red colour reflects the rigors of the ideals or desires of the colour enthusiast and has the ability to attract attention. These meanings are strongly felt by him. From another perspective, red also gives negative feel like aggressive, conflicting, competing, dominating, violent, emotional, and anxiety.

Apart from that, some male interviewee also stated that the colours did not holds specific meaning. Nevertheless, they argue that the choice of car colours has several reasons. The reasons are, for example, being trendy. And so, the resale the price is still relatively high. If a car is painted using colours that are widely used, it will sell quickly. Interviewee who think that way are the one who frequently change cars (replacing for every two years or reselling for every four or five years). The most comfortable time to enjoy a new car is when it is below five years old. After five years usually there are technical problems. As the car slowly accumulates defect, he can no longer feeling comfortable. Because of this, he usually sell his latest car no later than five years after being used. Therefore, he prefer to chose a colour that was trending at that time.

Regarding silver, the reason the interviewee chose silver is because when it is dirty, it is not that visible. Another reason, at the time of interview, silver is on popular demand. A similar reason was conveyed by interviewee named GBW, who prefer the colour of the car to be silver because the colour is not so visible after exposed to rain. Silver cars are not like black and white cars, which when exposed to rain and mixed with dust is very visible.

For the red colour, the interviewee who likes the car in red is because of its familiarity on almost every traffic. Along with green and yellow, the red colour is reminiscent of 
traffic lights. There are also those who like blood-like red albeit for different reason. He only wants red because it is a bright colour. As an artist, interviewee Mr feels proud when he own a red car. In addition to those reason, the red colour looks sparkling, clean, not easy to get dirty, and takes attention when under bright sun.

In perspective of female interviewee regarding the colour of the car, they have a slightly different opinion from male informants. Similar to male interviewee, there are female interviewees who like black colour in their car. Black, according to some, symbolizes gallantry, elegance, splendor, long-sighted, more elegant, and looks great or luxurious. It shows that there are women who like dashing cars, which usually opted by men. This preference are voiced by tall woman as jeep and other high car are comfortable because of the large room for legs. The car design becomes even more assertive when combined with black. Another reason, albeit simple, is to have different appearance than their peers.

Silver colour is interpreted by $\mathrm{EH}$ as charismatic and clean. Colour that is almost similar to silver is white. Interviewee who prefer white cars feels that the car as both beautiful and pleasing to the eye according to $\mathrm{MH}$. Although she likes a dashing car (because of her posture), she agreed that white is beautiful, besides being clean and sleek. This particular interpretation are close to feminine traits. Therefore she prefers the dashing white car.

The following interviewee likes both black and yellow, but if she have to choose one SM will choose yellow. To her, black colour means manly, while yellow means very cool. Even so, both colour still holds a beautiful impression. Similar to SM, SR prefers a car that was dashing according to her posture but with additional element in beauty.

There are also female interviewees who do not have preference towards the colour of the car for several reasons. One of the reason is when a particular colour becomes current trend, similar to what have been voiced earlier to some male interviewee, also about resell value. The reselling price that is not falling compared to other colours is also one of the reasons why $\mathrm{SH}$ do not paid much attention about colour. A different reason is because of easy maintenance, eye health reason ( asked by doctors to often see the colour green), visibility from afar for bright colour (silver and white), or visibility of the rear end of car.

And thus, male and female perspective was relatively similar in the car colour selection. When referring to the division of colour psychology groups, both male and female interviewee partly fall into the first group, where warm colour grouped into; some belong to the second group, the colour that is considered passive. The group between the two is green. There are also male and female interviewees who like this particular colour, 
although the reasons are different. NAS, he reasoned that the colour of dark green if dirty was not very visible, while UPA chose the colour as it was ordered from her doctor.

Conclusions related to the colour choice of interviewees, selection of colours is strongly influenced by the experience of using a car, knowledge of the car market, and the habit of frequently changing cars from each person. This conclusion applies to those who have no strong preference towards colour of their cars as it is just part of the car. Even so, there were some interviewees who had several bad experiences with their red cars, as told by IS and ATR that they experienced terrifying contact with truck. It made them strongly avoids red colour when choosing cars.

Basically, colour is only an attribute that complement the car. We can use another perspective by taking understanding that horse or turangga was a popular form of transportation in the past. It turns out that the turangga is also coloured. Some are white, black, or brown. The colours of the horse apparently also affect its price tag, in addition to its physical attributes. From this point of view, the final colour is no longer merely a complement but becomes an inseparable part and still must be considered, whatever the reason are.

Regarding colour, informants WM, S, HY, AS, and AH think that car colours do means something. In their case, they chose black because it looks fierce, elegant, authoritative, and when given accessories black tends to be elegant or scary. This opinion is different from $\mathrm{KL}, \mathrm{Mg}, \mathrm{SM}$, and $\mathrm{KPS}$, who argue that the white colour is instead the masculine option, is considered to be pretty, bright, clean, and shiny. In other case, Mr chose the colour red because he feels that red is appropriate colour for cleanliness, sparkling and brave. For female perspective, ES and EH were in the opinion that the silver feels elegant, charismatic, while black looked cool and dashing. MH has a different opinion. For him, white colour looks beautiful and manly. Regarding beautiful colours, it turns out that SM has a different opinion. To him, yellow colour is beautiful and cool. Based on this observation, the colour of car is considered to have symbolic meaning.

In addition, regarding the views of men and women on cars, it was mentioned that the types of cars have symbolic meanings. For example, MH said "Escudo is a dashing car." Another informant, KPS, said "Robicon Jeep is handsome and handsome." The two types of cars delivered by the informant were jeeps. This means that the jeep is a symbol of gallantry. Another type, sedan, WM informant said that "... the type of sedan is feminine, elegant, authoritative." If related to the position, for example, the president, chancellor, and prime minister use this type of sedan for their daily vehicles. So, this type of car can have symbolic meaning, which is emphasized by the colour of the car. 
In addition to this information, there were also interviewees who gave names to their cars. Some female interviewees use Klepon, Sekudo, Si Hitam Cantik (the Beautiful Black), Black, and Si Mungil (The Tiny) to name their cars. Meanwhile, there was a male interviewee who named his car Gagak Rimang (Crow Rimang).

\subsection{Cars as Signs in Gender Perspectives}

Based on the interviewee interpreter, there are several interpreters that appears to only apply to male interviewees; conversely there are interpreter that only apply to females. Interpreters that apply to males is that cars as an automotive education and as kelangenan.

For interpreter idea of cars as an automotive education, there are no female informants that have deep knowledge about automotive field. All female interviewees do not have much understanding when topic about automotive is brought up. When they encounter problems in their car, they prefer to let their husbands know or send it to maintenance workshop. For those who are no longer have husbands, they quickly send it to be repaired or sometimes ask their children to help solve the problem. With this level of dependency towards husbands it is no surprise that none of them have preference towards car for kelangenan.

Meanwhile, interpreter idea that apparently applies only to women is car as nurturing element. SM, a female interviewee, have this in her mind. This is of course have very close relationship to Javanese norm and culture where the mothers are expected to take care of their children, especially education. It comes from idea that female provides their children needs in form of breastfeeding, something that male not capable of.

Besides these two sample in male and one in female, other interpreters apply to both male and female. However, differences do exist as attitudes between male and female in responding to their personal car is not exactly similar. The first point is in the form of giving their car a nickname. Regarding this, female interviewees were more likely to give names than their male counterparts because for female interviewees, they felt that it made them feel closer relationship to their car. Some of them gave the nickname "Klepon", because the colour of the car was green, "Si Hitam" or "The Black One" because it was black, "Si Biru" or "The Blue One" because it was blue, "Si Mungil" or "The Tiny One" because of its small shape. For male interviewees, there was only one person who gave a nickname to his car, "Gagak Rimang", because it was black and agile, like the name of horse of former King of Demak Harya Penangsang. He chose the name because he really admired the big horse of Gagak Rimang even though his 
car was not a big car like the Pajero Sport. Instead, his car was Mitsubishi Outlander, a small car.

When it is about dealing with dents, female interviewees are easily feel uncomfortable if they see even a small dents on their car and so they make sure that those problems receive immediate attention. Male interviewees however, usually are quite patient about this issue, able to tolerate surface damage before performing a repairing procedure. This approach seems also have relationship to Javanese culture which considers women as symbols of beauty, neatness, subtlety, and the like. As a result, when there are things that are not in accordance with that view, women pays attention to it and takes action to fix it, including when addressing their personal cars.

Finally, when it is about lending the car, female interviewees are more likely to show reluctance than males. They worry that their car is not treated or used properly. They want their cars back as soon as the purposes have been fulfilled. Furthermore, when their car returns, female interviewees have urge to immediately examine their car, making sure that there is nothing serious happened to it. They feel more at ease if the borrower is their husbands or families because the feeling of detachment is not too high.

\section{Conclusion}

Based on the analysis of Peircean Semiotics, there are three conclusions.

1. Based on Peirce's category, private cars are considered indexes, symbols, and indexes as well as symbols.

2. There are only slight differences in male and female interviewees response towards how they feel about their cars.

3. Some male interviewees like car that shows femininity while some female interviewees like private cars that is considered manly.

\section{References}

[1] Amirat, K. (2012). The Consumer's Behavior in the Arms of Semiotics: New Revelations. Journal of Marketing Research \& Case Studies, vol. 2012, no.1, 12.

[2] Christomy, T. (2010). Peircean dan Kajian Budaya. In Semiotika Budaya. Depok: Pusat Penelitian Kemasyarakatan dan Budaya Fakultas IImu Pengetahuan Budaya Universitas Indonesia, pp. 109-145. 
[3] Fatchan, A. (2011). Metode Penelitian Kualitatif: Beserta Contoh Proposal Skripsi, Tesis, dan Desertasi. Surabaya: Jenggala Pustaka Utama.

[4] Handayani, C. S. and Novianto, A. (2008). Kuasa Wanita Jawa. Yogyakarta: LKiS.

[5] Herusatoto, B. (2000). Simbolisme dalam Budaya Jawa. Yogyakarta: PT. Hanindita Graha Widia.

[6] Hoed, B. H. (2011). Semiotika dan Dinamika Sosial Budaya. Jakarta: Komunitas Bambu.

[7] Moleong, L. J. (2007). Metodologi Penelitian Kualitatif. Bandung: PT Remaja Rosdakarya.

[8] Peräkylä, A. (2004). Reliability and Validity in Research Based on Naturally Occurring Social Interaction. In David Silverman (Ed.). Qualitative Research: Theory, Method and Practice. (2 ${ }^{\text {nd }}$ Edition). London: Sage Publications, pp. 283-304.

[9] Santosa, I. B. (2012). Nasihat Hidup Orang Jawa. Jogjakarta: DIVA Press.

[10] Schiffman, L. and Kanuk, L. L. (2008). Perilaku konsumen. Alih bahasa Zoelkifli Kasip. New Jersey: Indeks.

[11] Suryadi, A. G. L. (1993). Regol Megal Megol: Fenomena Kosmogoni Jawa. Yogyakarta: Andi Offset.

[12] Zoest, A. V. (1993). Semiotika: Tentang Tanda, Cara Kerjanya dan Apa yangKita Lakukan Dengannya. Jakarta: Yayasan Sumber Agung. 